\title{
GANHOS PERCEBIDOS POR PEQUENOS PRODUTORES RURAIS COOPERADOS A PARTIR DA CERTIFICAÇÃO FAIRTRADE
}

\author{
Vanusa Golçalves Toledo ${ }^{1}$ \\ Nicole Maccali ${ }^{2}$ \\ Marcia Cassitas Hino 3
}

\begin{abstract}
RESUMO
Este estudo tem por objetivo identificar os ganhos percebidos por pequenos produtores rurais cooperados a partir da certificação fairtrade. A economia global clama pela sustentabilidade como forma de proteção e presenvação do planeta. Diversas boas práticas tem se consolidado nesse sentido, ampliando modelos de gestão organizacionais com uma perspectiva mais sustentável. A natureza desta pesquisa é qualitativa, com caráter descritivo, sendo o estudo de caso norteado por dados primários, obtidos por meio de entrevistas, e secundários, obtidos por meio de documentos cedidos pela cooperativa. Os resultados demonstraram que a certificação trouxe aos pequenos produtores maior empoderamento sobre o seu processo de trabalho, melhorias na qualidade de vida dos produtores, de seus familiares e também dos trabalhadores, a partir da oportunidade de comercializar o seu produto com preço justo. Ainda, verificou-se benefícios para o meio ambiente, pois ao cumprirem os critérios exigidos pela certificadora passaram a adotar práticas sustentáveis no processo produtivo. Evidenciou-se assim, a partir da pesquisa, os ganhos econômicos, sociais e ambientais obtidos a partir de uma certificação vinculada a sustentabilidade.
\end{abstract}

Palavras-chave: Sustentabilidade. Comércio Justo. Certificação Fairtrade. Pequenos Produtores.

\footnotetext{
1 Mestre em Governança e Sustentabilidade pelo Instituto Superior de Administração e Economia (ISAE). E-mail: vanusatoledo@hotmail.com ORCID: https://orcid.org/0000-0003-0529-3095

2 Doutora em Administração pela Universidade Federal do Paraná (UFPR, 2011). E-mail: nicole.maccali@gmail.com ORCID: https://orcid.org/0000-0003-0383-6834

${ }^{3}$ Doutora em Administração de Empresas pela Fundação Getúlio Vargas (FGV/EAESP, 2018). Pósdoutoranda em Administração de Empresas na Universidade Positivo. E-mail: marciahino@uol.com.br ORCID: https://orcid.org/0000-0001-5763-3456
}

R. gest. sust. ambient., Florianópolis, v. 10, n. 2, p. 25-44, jun. 2021. 


\title{
PERCEIVED GAINS BY SMALL RURAL PRODUCERS COOPERATED FROM FAIRTRADE CERTIFICATION
}

\begin{abstract}
This study aims to identify the gains perceived by small cooperative farmers based on Fairtrade certification. The sustainability theme is directly linked to the global economy and has been gaining space in the management models of organizations with an inclination towards sustainable development, becoming a good practice in the current situation of the planet. The nature of this research is qualitative, with a descriptive character, the case study being guided by primary data, obtained through interviews, and secondary, obtained through documents provided by the cooperative. The results showed that the certification brought small producers greater empowerment over their work process, improvements in the quality of life for producers, their families and workers, from the opportunity to market their product at a fair price. Still, it brought benefits to the environment, since when fulfilling the criteria required by the certifier, they started to adopt sustainable practices in the production process. Thus, it was evident, from the research, the economic, social and environmental gains obtained from a certification linked to sustainability.
\end{abstract}

Keywords: Sustainability. Fair Trade. FairTrade Certification. Small Farmers.

\section{INTRODUÇÃO}

Um dos grandes desafios das organizações contemporâneas tem se situado em quantificar a relação entre as atitudes e atuações de cunho sustentável e os lucros (MUNCK, 2013). Uma sociedade ou comunidade que promove a sustentabilidade pode ser descrita como aquela em que os indivíduos possuem o senso de iniciativa e solidariedade (PATRICIO, GOMES, 2013; ARAÚJO, 2018).

A sociedade atual tem vivido momentos de instabilidade econômica, impactando de certa forma os grandes produtores rurais e com mais intensidade, os pequenos produtores, resultando em receitas mínimas para o pequeno produtor e dificultando a sua permanência no campo e o sustento familiar. É nesse contexto que o comércio justo aparece como alternativa para a construção de uma economia justa, que oportunize a agricultura familiar e um desenvolvimento includente e sustentável. A constituição e as estratégias de sustentabilidade são norteados basicamente pelo equilíbrio de fatores econômicos, sociais e ambientais e solicitam uma estrutura tecnológica, institucional e base legal dinâmica, de maneira a instalar a imperiosa

R. gest. sust. ambient., Florianópolis, v. 10, n. 2, p. 25-44, jun. 2021. 
harmonia e a verdadeira gestão ambiental (PATRÍCIO, GOMES, 2013; ARAÚJO, 2008).

Sachs (2008) pondera que o desafio é mudar pequenos produtores em corporações instituídas de pequena escala, com capacidade de concorrer no comércio capitalista. O desenvolvimento includente solicita, acima de tudo, o abono do aprendizado dos direitos civis, cívicos e políticos. Sendo assim, o pequeno produtor se fortalece com a inserção em uma cooperativa, pois seus direitos civis serão validados e aprenderá outros conceitos, como direitos cívicos e políticos. Com a inserção do pequeno produtor na cooperativa, ele passa a ter direitos e deveres como cooperado, e um desses benefícios é a inclusão no comércio justo e solidário. $O$ comércio justo tem sido um movimento mundial que, diante da problemática que tem envolvido os pequenos produtores, busca diminuir a marginalização do produtor, pois alguns produtores estavam permanecendo à margem da sociedade, pelo capitalismo competitivo (WANG, CHEN, 2019; BARBIERI et al., 2014).

O capitalismo consciente é um paradigma em desenvolvimento para as relações comerciais que fomenta diversos tipos de valores e bem-estar para todas as pessoas envolvidas: financeiro, intelectual, físico, ecológico, social, cultural e emocional, ético e até mesmo espiritual (MACKEY, SISODIA, 2013). Os autores argumentam que a prática do capitalismo consciente não se sintetiza a ser correto ou trabalhar bem para realizar o bem (FRÉMEAUX, MICHELSON, 2017). Ela vai além do fundamento empresarial e de como ela pode cunhar mais valor (BEGNINI et al., 2019). A proposta compreende o posicionamento dos comércios em consonância com a natureza humana, reconhecendo que os bens naturais são finitos, necessitando ser resguardados e conservados.

Vários movimentos aconteceram até chegar aos selos de sustentabilidade, que visam certificar as produções que seguem determinados requisitos, bem como remuneram de forma diferenciada esses produtos. Neste conexto de certificações, temos a Fairtrade 4 que estabelece critérios para que esses produtores sejam beneficiados com o comércio justo e solidário. Dentre esses critérios, encontram-se a preocupação com a sustentabilidade, a ética na produção e o benefício de produtores e trabalhadores. Tal certificação proporciona aos produtores maiores oportunidades

\footnotetext{
4 "Fairtrade, escrito junto, é o nome do selo, enquanto Fair Trade, escrito separado, é o fenômeno do comércio justo" (STELZER, GRANEMANN, 2019, p. 2)
}

R. gest. sust. ambient., Florianópolis, v. 10, n. 2, p. 25-44, jun. 2021. 
na venda de seus produtos e na aquisição de recursos que irão viabilizar o custeio de sua propriedade, além de promover a adoção de ações que visam a sustentabilidade do planeta.

A certificação Fairtrade tende a fazer com que o produtor trabalhe de uma forma correta com sua mão de obra e que, ao mesmo tempo, alcance mais lucro trabalhando assim. Dessa forma, faz-se necessário desmistificar que o desenvolvimento de propostas justas, tais como registro de funcionários com salários justos, cuidado com a propriedade, investimento em técnicas agrícolas e preservação do meio ambiente, trarão menores ganhos ou até mesmo prejuízo ao produtor rural. Ao contrário, a certificação, ou selo, prevê que o produtor e o trabalhador podem, sim, ter uma boa convivência e que ambos tenham ganhos ou empoderamento com independência, desenvolvendo práticas justas.

Nesse eixo, a sustentabilidade atrelada ao comércio justo proporciona proteção ambiental, oportuniza aos pequenos produtores rurais melhores condições de vida e a comercialização de seus produtos com maior rentabilidade, ou seja, um desenvolvimento sustentável. Com base no exposto, este estudo tem como objetivo identificar os ganhos percebidos por pequenos produtores rurais de uma cooperativa a partir de uma certificação vinculada a sustentabilidade.

\section{REVISÃO DE LITERATURA}

\subsection{SUSTENTABILIDADE}

Segundo Boff (2015), a sustentabilidade nasceu com a silvicultura e o manejo das florestas, em que o homem retirava madeiras delas para a construção de casas e móveis. O uso da madeira foi tão intenso em Portugal e na Espanha que as florestas começaram a escassear. Em 1560, na Alemanha, iniciaram as preocupações com o "uso racional das florestas, de forma que elas pudessem se regenerar e se manter permanentemente. Neste contexto surgiu a palavra alemã Nachhaltigkeit, que significa sustentabilidade" (BOFF, 2015, p. 32). Com esse novo olhar direcionado às questões ambientais, surgiu a preocupação de se estar efetuando conferências com diversos países, visando gerar alternativas de desenvolvimento que agregassem a preservação da natureza e dos recursos naturais.

R. gest. sust. ambient., Florianópolis, v. 10, n. 2, p. 25-44, jun. 2021. 
Um relatório criado pela Comissão Mundial sobre o Meio Ambiente e o Desenvolvimento (CMMAD) chamou a atenção do mundo sobre a necessidade de se encontrar novas formas de desenvolvimento econômico, sem danos ao meio ambiente. Além disso, o relatório estabeleceu três princípios básicos a serem cumpridos: desenvolvimento econômico, proteção ambiental e equidade social (GALINDO, WEISS, 2018). O relatório, ainda, ressalta a necessidade de descentralização das aplicações de recursos financeiros e humano. O documento foi chamado de Relatório de Brundtland 1987 e forneceu parâmetros para a conferência que seria realizada no Rio de Janeiro em 1992, a Eco 92 (PENÃFIEL, RADOMSKY, 2013).

Na perspectiva de Elkington (2020, p. 52) a sustentabilidade "é o princípio que assegura que nossas ações de hoje não limitarão a gama de opções econômicas, sociais e ambientais disponíveis para as futuras gerações". O autor compara o garfo com os três pilares da sustentabilidade e explica que os três dentes do garfo são: prosperidade econômica, qualidade ambiental e justiça social. O conceito de sustentabilidade é desenvolvido pautado nesses três pilares, em que "a sociedade depende da economia e a economia depende do ecossistema global, cuja saúde representa o pilar derradeiro" (ELKINGTON, 2020, p.110-111). Para o autor, eles não são estáveis; eles estão em um fluxo constante devido às pressões sociais, políticas, econômicas e ambientais, aos ciclos e conflitos.

Esses princípios vêm orientando o direito ambiental e a regulamentação decorrente da legislação ambiental, bem como protocolos e acordos setoriais firmados ao longo do tempo pelo ramo empresarial (MACÊDO et al., 2015).

Nos negócios, o tripé da sustentabilidade ganha a denominação de triple bottom line, consistindo em três Ps: profit (lucro, em português), people (pessoas) e planet (planeta). O tripé tem como intuito medir o desempenho financeiro durante um período de tempo. Elkington (2020), criador da expressão triple bottom line, pondera que as empresas precisam medir o valor que causam ou assolam no nível econômico, social e ambiental, o mesmo vale para demais empreendimentos, independente do porte e do segmento. Desta forma, compreende-se que o fortalecimento da agricultura de pequeno porte é essencial para que a sustentabilidade realmente aconteça, porém entende-se que para isso faz-se necessário prover formas para que os negócios sejam viáveis.

R. gest. sust. ambient., Florianópolis, v. 10, n. 2, p. 25-44, jun. 2021. 
A procura pela sustentabilidade na agricultura de pequeno porte é desafiadora por envolver diferentes níveis e a necessidade de articulação de pessoas que atuam no âmbito público e privado, pois a capacidade de competição com grandes produtores torna-se limitada em decorrência do volume e custos de produção. Neste contexto, surge a possibilidade de uma estrutura de certificação para o atendimento de nichos de mercado em ampliação, como a produção orgânica, onde valoriza-se o processo de produção de forma financeira. O comércio justo, em inglês Fair Trade, é uma possibilidade para os pequenos produtores sobreviverem diante da desigualdade que o comércio vem apresentando (SEBRAE, 2016), além de promover a adoção de práticas sustentáveis nestas propriedades.

\subsection{O COMÉRCIO JUSTO COMO UMA POSSIBILIDADE PARA OS PEQUENOS PRODUTORES RURAIS}

O comércio justo no Brasil teve seu início na década de 1970, quando ONGs europeias atreladas a igrejas ajudaram na organização de grupos de trabalhadores rurais e no comércio simples de artesanato (STELZER, GRANEMANN, 2019). O marco inicial do comércio justo brasileiro foi um projeto da Fairtrade Labelling Organization (FLO) com o Suco Justo, abarcando produtores de laranja de Paranavaí/PR. Mais tarde, o café foi incorporado ao comércio justo brasileiro (SANTOS et al. 2020).

O comércio justo surge dentro de um cenário como uma forma de se "premiar" os pequenos produtores que adotam práticas sustentáveis dentro da sua propriedade rural, não limitando essas práticas às ações do cultivo do solo, mas abordando questões sociais, econômicas e ambientais - o tripé da sustentabilidade. Esse prêmio, muitas vezes, vem por meio de uma remuneração diferenciada paga pelo seu produto.

Assim, os princípios que devem imperar em um relacionamento comercial avaliado como justo são os seguintes, de acordo com o Sebrae (2016):

1. Transparência e corresponsabilidade na gestão da cadeia produtiva e comercial;

2. Relação de longo prazo que ofereça treinamento e apoio aos produtores e acesso às informações do mercado;

3. Pagamento de preço justo no recebimento do produto, além de um bônus que deve beneficiar toda a comunidade, e de financiamento da produção ou do plantio, ou a antecipação do pagamento da safra, quando necessário;

4. Organização democrática dos produtores em cooperativas ou associações;

R. gest. sust. ambient., Florianópolis, v. 10, n. 2, p. 25-44, jun. 2021. 
5. Respeito à legislação e às normas (por exemplo, trabalhistas) nacionais e internacionais;

6. O ambiente de trabalho deve ser seguro e as crianças devem frequentar a escola;

7. O meio ambiente deve ser respeitado.

Alguns dos critérios com os quais uma organização (cooperativa ou associação), produtor ou uma companhia (empresa) precisam estar em conformidade para alcançar a certificação do comércio justo dado pela instituição autônoma FLOCERT GmbH (WFTO, 2019; STELZER, GRANEMANN, 2019; TAMBELINI, 2018) incluem: estar organizado em associações; ter processo de decisões democrático; ter igualdade entre homens e mulheres; colocar as crianças na escola; respeitar as leis trabalhistas; reduzir o uso de agrotóxicos; gerenciar resíduos; cuidar da fertilidade dos solos e dos recursos hídricos; não usar transgênicos; investir anualmente de $R \$ 4.100$ a $R \$ 7.700$ na certificação. E as empresas devem: comprar matérias-primas já certificadas; pagar um preço mínimo que possibilite a produção sustentável; pagar bônus para projetos sociais; financiar parte da produção, quando necessário; fazer contratos de longo termo que viabilizem práticas sustentáveis de produção; fazer contrato de licença com o Instituto Fairtrade Brasil; e investir anualmente de $R \$ 4.600$ a $R \$ 7.200$ na certificação, além de pagar uma taxa de licença trimestral de $R \$ 875$ ou de $1 \%$ das vendas (o que for maior).

Neste cenário, para estar inserido no comércio justo, o pequeno produtor rural tende a buscar o cooperativismo como forma de se tornar competitivo diante dos grandes produtores. Porém, mesmo dentro do cooperativismo o fator econômico é desigual. Ao mesmo tempo que grandes cooperativas faturam bilhões de dólares e conseguem distribuir grandes cifras de sobras (nome dado aos lucros que são repassados aos produtores), as pequenas cooperativas lutam para sobreviver nesse universo e buscam novas soluções. As cooperativas passam a atuar como articuladoras no suporte à comercialização dos produtos, uma vez que encaram o comércio justo como um instrumento fundamental para a diminuição da pobreza e para a aquisição de um elevado desenvolvimento sustentável (ARTESOL, 2017).

Os produtos que recebem a certificação Fairtrade são cultivados, manipulados, armazenados e transportados conforme os critérios da certificadora. Toda a produção disponibilizada pelos produtores necessita estar em conformidade com os critérios estabelecidos pela Fairtrade, pois a certificação traz a garantia de que o comprador

R. gest. sust. ambient., Florianópolis, v. 10, n. 2, p. 25-44, jun. 2021. 
estará adquirindo produtos de qualidade. A produção deve observar os aspectos socioambientais como garantia de forma de vida sustentável

Para uma organização estar devidamente certificada, existem condições indispensáveis que precisam ser cumpridas, tanto para se obter quanto para manter a certificação. As organizações de pequenos produtores precisam estar legalmente registradas, em conformidade com as leis que regem o comércio brasileiro. Não podem ser produtores individuais nem estar inseridos em grupos de produtores informais. Segundo a Fairtrade (2016), no mínimo a metade dos associados da organização que se candidata para obter a certificação Fairtrade precisa ser formada de pequenos produtores.

Dessa forma, o Fair Trade é uma perspectiva que o pequeno produtor tem como alternativa para comercializar seus produtos em meio ao comércio tradicional e se fundamenta na parceria entre produtores e consumidores, visando mais oportunidades para os pequenos produtores.O Fair Trade colabora ainda para o desenvolvimento sustentável ao propiciar melhores espécies de troca e a garantia dos direitos para fabricantes e trabalhadores marginalizados,sendo uma opção real e viável diante do sistema tradicional de comércio (SEBRAE, 2016).

\section{METODOLOGIA}

Para alcançar o objeto de investigação, o estudo procurou mostrar os ganhos obtidos a partir de uma certificação de sustentabilidade para pequenos produtores rurais cooperados a uma cooperativa, realizando-se um estudo de caso na Coacipar - Cooperativa de Agricultura Familiar e Solidária do Paraná (Coacipar), localizada no Município de Paranavaí - Estado do Paraná. Ressalta-se que a cooperativa onde o estudo de caso foi realizado é auditada pela FLO-CERT GmbH, uma empresa que presta serviço para a certificadora Fairtrade, ambas com sede na Alemanha.

Foram indicados pela Cooperativa 3 pequenos produtores (P1, P2 e P3) para realização das entrevistas semiestruturadas. Tais produtores eram colhedores de laranja e se tornaram produtores rurais, sendo atualmente proprietários da terra. Os produtores não possuem trabalhadores permanentes, pois eles mesmo trabalham na propriedade com a família, porém durante a safra contratam colhedores de laranja. Para a análise coletaram-se ainda relatórios financeiros dos produtores pesquisados, que se encontravam arquivados pela cooperativa, e demais documentos relativos as

R. gest. sust. ambient., Florianópolis, v. 10, n. 2, p. 25-44, jun. 2021. 
propriedades, conforme exigência da certificação, disponibilizados pelos próprios produtores rurais, sendo: Matrícula do Imóvel, Extrato de DAP (Certidão de Aptidão ao Programa Nacional de Fortalecimento da Agricultura Familiar - Pronaf), Recibo de Entrega da Declaração do Imposto Territorial Rural, Contrato Particular de Compromisso de Prestação de_Serviços de Colheita de Laranja, Ficha para Inserção na Cooperativa de Agricultura Familiar e Solidária do Paraná - Coacipar, Relatório Semestral de Vistorias de Plantas Hospedeiras do Agente Causal do Huanglongbing HLB ou Greening - Inspeção pelo proprietário, certificados de cursos e treinamentos que os produtores efetuaram pela cooperativa, Comprovante de Devolução de Embalagens Vazias de Agrotóxicos na Associação dos Distribuidores de Insumos e Tecnologia Agropecuária (Adita).

As entrevistas foram realizadas nas propriedades rurais com os 3 produtores e um trabalhador rural, contratado para um serviço pontual em uma das propriedades, com duração aproximada de 3 horas cada. Durante o processo de entrevistas, os produtores apresentaram as propriedades, relatando como eram antes e como se tornaram depois da certificação, e fotos foram coletas e tiradas pelo pesquisador demonstrando os impactos da certificação nas propriedades.

\section{APRESENTAÇÃO E ANÁLISE DOS DADOS}

\subsection{O PROCESSO DE OBTENÇÃO DA CERTIFICAÇÃO FAIR TRADE PELA COOPERATIVA COACIPAR}

Em julho de 2011, nasceu a Cooperativa de Agricultura Familiar e Solidária do Paraná (Coacipar), localizada no Município de Paranavaí, no Paraná, cuja missão é "Promover o crescimento dos cooperados através de ações que desenvolvam sua produção de maneira sustentável, agregando valores econômicos, ambientais e sociais", e que possui como visão "Ter cooperados satisfeitos sendo referência de produção e comercialização dentro do comércio justo".

No início de 2012, com a cooperativa já com toda a sua documentação registrada nos órgãos públicos, após uma auditoria inicial, a Coacipar recebeu a permissão para a comercialização e conseguiu fazer uma parceria com uma indústria de processamento de laranja no município de Paranavaí. Assim, a indústria com todo o seu conhecimento de anos somado ao conhecimento dos produtores conseguiu

R. gest. sust. ambient., Florianópolis, v. 10, n. 2, p. 25-44, jun. 2021. 
produzir um suco de laranja com procedência e qualidade garantidas, além de um sabor inigualável. Para que essa parceria desse certo, foi preciso muita dedicação, conhecimento técnico e a união de produtores e trabalhadores rurais na justa medida para que se obtivesse um trabalho diferenciado de outras indústrias e organizações. Assim, a indústria aceitou produzir o suco rastreado, com a cooperativa trabalhando para cumprir os critérios.

Mas, para chegar ao panorama da atualidade, os cooperados tiveram de aprender a fazer a gestão do negócio, sempre buscando aprendizado em conjunto com o diálogo, a transparência e o respeito, que são os três pilares que alicerçam a sólida base da Coacipar, sempre acreditando que, mais do que cooperados, eles fazem parte de um negócio que realmente pertence a eles e buscando sempre a justiça pela democracia, sendo tudo decidido em reuniões e assembleias com o voto dos cooperados.

A Coacipar desenvolve o conceito original do cooperativismo, trabalha com o cooperado e, em função dele, a democracia é realmente levada a sério. Essa transparência e respeito na gestão são um dos critérios que garante o direito ao uso do selo Fairtrade. A cooperativa também orienta constantemente os seus cooperados para que eles mantenham um ambiente de trabalho saudável, sempre respeitando as normas de segurança e proporcionando todas as facilidades que os trabalhadores têm por direito: a Coacipar, além de ter um certificado que permite a venda da laranja certificada, conseguiu, em 2015, a autorização para fazer a comercialização de suco pasteurizado e envasado, pronto para beber, nos mercados/comércios no Brasil por meio da Associação Brasileira de Comércio Justo (ABCJ).

Atualmente, a cooperativa possui 53 cooperados, os quais seguem os preceitos do comércio justo. Nesse contexto, dentre os tantos cooperados que a cooperativa possui, os três produtores que participaram da pesquisa foram selecionados por se destacarem entre os demais, pois eram trabalhadores rurais e se tornaram pequenos produtores. Assim, são considerados empreendedores, pois iniciaram suas atividades como trabalhadores rurais, depois foram participar de uma associação e perceberam que ser proprietário da terra era um bom negócio, foram atrás de conquistar uma nova perspectiva de vida, pois a associação conseguia oportunizar isso a eles. Desse modo, buscaram apoio do governo federal por meio do Programa Banco da Terra e conseguiram se tornar proprietários.

R. gest. sust. ambient., Florianópolis, v. 10, n. 2, p. 25-44, jun. 2021. 
Com base no exposto, para que os produtores usufruam dos benefícios da certificação, é preciso que sejam cooperados de uma organização que possui a certificação, pois é por meio dela que os pequenos produtores conseguem a certificação. No entanto, a propriedade necessita estar em conformidade com os critérios estabelecidos pela certificadora.

\title{
4.2 PERCEPÇÃO DOS PEQUENOS PRODUTORES SOBRE A CERTIFICAÇÃO
}

O Produtor 1 (P1) relata que, em relação aos critérios, para ela é tudo novo e tem conhecimento de que são muitos e que devem ser cumpridos. Sabe que deve manter a propriedade organizada da forma que exigem os critérios e ainda fala que não está sendo fácil. A entrevistada diz que acredita que, com o passar do tempo, ela irá conseguir cumprir todos os critérios. Relata que hoje tem mais consciência do que se deve fazer em relação ao meio ambiente, efetua a separação do lixo, o reciclado tem sua destinação correta e o orgânico enterra ou utiliza na propriedade (na horta, vasos de flores etc.).

Tenho conhecimento, pois participamos das reuniões e em todas sempre nos orientam, e consigo controlar se estou fazendo certo ou não, quando o técnico da cooperativa vem fazer vistoria na propriedade e fala se encontrou alguma coisa fora do lugar, e se sim nos orienta para que possamos organizar. (P1).

Em relação aos critérios da certificadora Fairtrade, o Produtor 2 (P2) diz ter conhecimento de alguns, pois são muitos. Vem conseguindo cumprir os critérios com a orientação do técnico da cooperativa. Já fez alguns cursos, treinamentos e sempre está recebendo orientações técnicas para cumprir os critérios.

\begin{abstract}
Atualmente, tenho a oportunidade de fazer diversos cursos, por exemplo sobre pragas e doenças da laranja, curso da NR 31 de como se proteger na hora de passar os venenos na laranja. Já realizei o curso sobre os cuidados com a terra (solo), treinamento sobre os direitos dos trabalhadores rurais, todos que prestam serviço na propriedade na época da colheita têm de ser registrados e tenho de recolher todos os encargos trabalhistas. Dentro do local onde armazenamos os agroquímicos, implantamos placas de identificação dos produtos que são utilizados na propriedade; antes de iniciar a colheita, tanto o produtor como um encarregado dos colhedores realizam o treinamento de primeiro socorros, pois se acontecer um acidente durante a colheita eles possuem conhecimento para intervir até a chegada do socorro (P2).
\end{abstract}

O Produtor 3 (P3) afirma conhecer critérios, mas relatou que não está conseguindo cumprir todos, está sempre atento em sua propriedade se está

R. gest. sust. ambient., Florianópolis, v. 10, n. 2, p. 25-44, jun. 2021. 
cumprindo os critérios e sempre pede ajuda para o técnico (da Cooperativa), que o orienta sobre como deverá fazer para cumpri-los.

São muitos, mas conheço sim, quando chego à propriedade e vejo que não tem lixo esparramado, tenho cuidado na hora de passar os produtos na laranja, uso o macacão, os óculos e as luva, e sempre em reuniões e assembleias é falado sobre os cuidados que nós temos de ter com a propriedade, e a gente tem de ficar vigiando constantemente nós mesmos para não deixar a propriedade bagunçada (P3).

Para manter a certificação é necessário seguir todos os critérios impostos pela certificadora, e tais critérios permeiam práticas sustentáveis, evidenciadas a adoção nas falas dos entrevistados.

O que mais procuramos manter em dia é a limpeza na propriedade, a organização, antes da safra registrar os trabalhadores, fazer os cursos de NR 31, inspeção de pragas e doenças, de solo e água, quando iniciamos a safra os trabalhadores têm de ter feito o curso de colheita de laranjas, curso de primeiros socorros (P1).

O que mais tenho em mente é o cuidado com a organização da propriedade. Antes de participar da cooperativa, eu nunca liguei para a organização da minha propriedade, deixava tudo de qualquer jeito, quando ia passar algum produto na laranja, as embalagens eu deixava no terreiro, muitas vezes eu juntava os lixos da propriedade e queimava, muitas das vezes até embalagens de agroquímicos também, antes eu não tinha consciência de que não poderia, hoje tenho a oportunidade de fazer curso sobre pragas e doenças da laranja, curso da NR 31 de como devo me proteger na hora de passar os venenos na laranja, já fiz curso sobre os cuidados com a terra (solo), pois a nossa região tem muita erosão e temos de cuidar da propriedade. Hoje já tenho mais consciência em relação aos colhedores de laranja, todos que prestam serviço na minha propriedade na época da colheita são registrados e eu recolho todos os encargos que o sindicado manda, tenho de colocar plaquinhas de identificação nas prateleiras, agora faço treinamento de primeiros socorros antes da colheita, pois se acontecer um acidente durante tenho como ajudar até chegar o socorro (P2).

Não se pode usar produtos proibidos, tem de deixar a propriedade bem organizada, devolver as embalagens vazias, quando for fazer a colheita tem de contratar o colhedor e registrar, tem de cuidar do meio ambiente, tem de fazer os treinamentos que a cooperativa oferece (P3).

Evidencia-se que os produtores sabem da importância dos critérios, e que tais minimizam os efeitos dos produtos químicos no ser humano. Para os entrevistados, apesar de lidar com produtos agroquímicos perigosos, preocupam-se com o fato de não precisar usá-los também.

O critério mais difícil é reduzir o uso de agroquímico na lavoura, sabemos que seria bom que nem precisássemos deles, porém não tem como termos produção de laranja orgânica na nossa região devido ao clima, e com essas temperaturas elevadas não tem como controlarmos as doenças no pomar. $O$ critério mais fácil de seguir é a forma que devemos trabalhar, com mão de obra formalizada, não ter trabalho infantil, e para nós, que já fomos trabalhadores, isso é muito bom exemplo (P1).

R. gest. sust. ambient., Florianópolis, v. 10, n. 2, p. 25-44, jun. 2021. 
O que eu acho mais difícil é não poder usar alguns produtos na laranja, porque muitas das vezes esses produtos são até mais baratos do que outros, mas sei que é para proteger a minha saúde que não posso usar. A auditoria uma vez explicou para mim que a certificação se preocupa com a saúde do produtor e de todos os que entram na propriedade. O mais fácil para mim realmente são os treinamentos, pois participo ativamente da gestão da cooperativa (P3).

Em suas falas, os produtores ressaltavam e buscavam apresentar, nas visitas as propriedades, os ganhos que tiveram com a ceritificação, impactando nos diferentes eixos de suas vidas. A Produtora 1 ressalta que antes de se cooperar teve prejuízos com a comercialização dos produtos.

Na cooperativa conseguimos ver que somos valorizados em relação ao preço pago pela nossa laranja e por sermos tratados de forma mais humana que se estivéssemos em uma cooperativa grande, e vejo que tudo isso é o próprio selo também que exige a forma que temos de ser tratados (P1).

O Produtor 2 relata que não conhece outra cooperativa que paga o mesmo valor pela caixa de laranja que a Coacipar - "hoje eu entrego na cooperativa minha laranja com um preço maior do que se eu entregasse para outras cooperativas" (P2).

Quando eu entrei na cooperativa, eu não acreditava que era do jeito que meu amigo falava, e quando comecei a entregar minha laranja e receber vi que eu já conseguiria fazer várias mudanças na minha propriedade. Já pude comprar um trator, pois eu tinha certeza de que iria conseguir pagar, e comprei outros equipamentos que eu não tinha, vivia emprestando dos vizinhos, e muitas vezes até pagava aluguel pelo implemento, mas hoje já consigo planejar o que vou investir, o meu pomar está tendo uma melhor rentabilidade do que antes (P3).

Durante as entrevistas, percebeu-se que os produtores não conseguem ter um planejamento de vendas, e com isso não conseguem controlar suas entradas, contando com o apoio da cooperativa neste controle.

Eu perdia muito vendendo para um e para outro comprador, agora que estou na cooperativa tenho certeza de que tudo o que eu entregar na cooperativa vou receber pontualmente e por um preço justo, agora consigo comprar o que preciso e pagar em dia, e já penso em plantar mais laranja (P3).

Os produtores entrevistados relatam que atualmente têm um padrão de vida melhor do que antes e que conseguem visualizar o resultado do trabalho deles. Destacam ainda melhora na relação familiar a partir das mudanças e ganhos obtidos.

Nós conseguimos melhorar o padrão de vida da nossa família. Hoje já conseguimos trocar o trator, comprar uma máquina para esparramarmos os adubos, o que antes era feito manualmente. Hoje podemos viajar com toda a

R. gest. sust. ambient., Florianópolis, v. 10, n. 2, p. 25-44, jun. 2021. 
família, podemos dar mais qualidade de vida aos nosso filhos, pagar cursos de inglês para eles (P1).

Eu consegui melhorar minha vida em vários sentidos. Pude trocar meu carro, agora consigo comprar mais produtos para passar na laranja e, com isso, melhorou a qualidade da fruta no pomar, posso até ajudar meus parentes. Muitas coisas boas estão acontecendo na minha vida, tenho até planos para, futuramente, comprar mais terra e plantar mais laranja. Os colhedores de laranja ficam esperando o início da safra para vir colher laranja na minha propriedade (P3).

Os produtores relatam que os trabalhadores também participam dos ganhos do comércio justo. Os trabalhadores recebem os mesmos cursos e treinamentos que os produtores. A partir da certificação, os trabalhadores passaram a ser registrados, recebem os treinamentos da cooperativa, recebem equipamentos de proteção individual e um valor adicional em dinheiro por caixa colhida.

Com certeza, eles ganham mais por colherem laranja dos produtores da Coacipar, e hoje, como sou produtor e já fui colhedor, vejo que os colhedores são tratados com mais respeito, e isso é uma exigência da certificação. E é bom ver que os trabalhadores são valorizados e, quem sabe, eles também podem virar produtores como eu (P1).

Os entrevistados explicitam que os critérios não são fáceis para eles cumprirem, pois têm baixa escolaridade, porém que em decorrência dos ganhos, tanto financeiro quanto familiares, buscam manter-se cooperados.

Hoje, não consigo me ver sem a certificação. Apesar de cada dia que passa
os critérios ficarem mais difíceis, vejo que, se nós pegarmos o hábito de
estarmos sempre fazendo tudo certo, isso vira rotina e, com o passar do
tempo, não iremos mais ver dificuldade em cumpri-los. O selo é muito
importante para nós, pequenos produtores, pois por meio dele conseguimos
alcançar um objetivo, que é melhorar a qualidade de vida da nossa família, e
o selo consegue proporcionar isso para nós, e o mais importante: com a
dignidade do nosso trabalho (P1).

$\mathrm{Na}$ entrevista com o trabalhador foi possível evidenciar mudanças na relação dos produtores com estes, demonstrando o ganho social obtido a partir da certificação.

Depois que meu patrão começou a entregar laranja na cooperativa, até a forma que ele trata os seus trabalhadores melhorou, ele dá mais atenção aos colhedores (Fala do trabalhador entrevistado).

Para o entrevistado, a certificação Fairtrade é muito importante para trabalhadores como ele, pois por meio dela o trabalhador se sente mais seguro no trabalho, tem a certeza de seus direitos garantidos. Evidenciou ainda a disponibilização dos equipamentos necessários para uma melhor qualidade de vida melhor ao trabalhador durante o trabalho.

R. gest. sust. ambient., Florianópolis, v. 10, n. 2, p. 25-44, jun. 2021. 
O registro em carteira é bom, pois se eu ficar doente posso me tratar e não perco dia de serviço, e tenho a certeza de que vou conseguir me aposentar quando chegar o tempo (Fala do trabalhador entrevistado).

O produtor sempre fala que tem de cumprir um monte de regras para conseguir um preço melhor pela laranja. Sei que ele comprou banheiros e colocou na roça para nós. Agora todo início da colheita ele dá marmita e garrafão de água para todo mundo. Na hora que paramos para comer, temos de sentar na mesa embaixo da tenda que ele colocou na roça, nós não gostamos muito não, mas fazemos do jeito que o produtor pediu, pois entendemos que aquelas exigências são necessárias." (Fala do trabalhador entrevistado).

Complementarmente as entrevistas, buscou-se, por meio de dados históricos, demonstrar com dados financeiros os ganhos obtidos a partir da certificação demonstrados no quadro abaixo. Tais valores evidenciam que práticas sustentáveis podem refletir também em ganhos financeiros, porém o reflexo dá-se em toda a cadeia produtiva.

Quadro 1- Comparação de ganhos financeiros

\begin{tabular}{|c|c|c|}
\hline Ano-safra & Coacipar R\$ & Outros R\$ \\
\hline $2013 / 2014$ & 11,17 & 10,00 \\
\hline $2014 / 2015$ & 12,57 & 10,00 \\
\hline $2015 / 2016$ & 17,52 & 11,00 \\
\hline $2016 / 2017$ & 15,53 & 14,50 \\
\hline $2017 / 2018$ & 21,00 & 20,00 \\
\hline
\end{tabular}

Fonte: arquivo Coacipar, 2018.

Para os produtores entrevistados, os ganhos econômicos são fundamentais para a subsistência deles dentro da propriedade. Com uma rentabilidade maior, eles conseguem investir mais na propriedade e planejar o futuro.

A partir das falas dos entrevistados e dos dados analisados, foi possível evidenciar alguns ganhos a partir da certificação, impulsionados não somente pelos ganhos econômicos, mas também pelo desenvolvimento social e ambiental nas pequenas propriedades.

Os ganhos ambientais foram observados nos cuidados com o solo. A Produtora 1 hoje tem mais consciência sobre os cuidados necessários na hora de abastecer 0 pulverizador, tentando evitar qualquer contaminação do solo com resíduos químicos.

R. gest. sust. ambient., Florianópolis, v. 10, n. 2, p. 25-44, jun. 2021. 
Antes da certificação Fairtrade, conforme visualiza-se na Figura 1, o local (tulha) onde o produtor guardava os seus produtos agroquímicos na propriedade não possuia nenhuma segurança. Com a certificação, o produtor passou a ter mais consciência sobre como devem ser armazenados os seus agroquímicos (Figura 1).

Figura 1 - Armazenagem de agroquímicos: antes e após a certificação

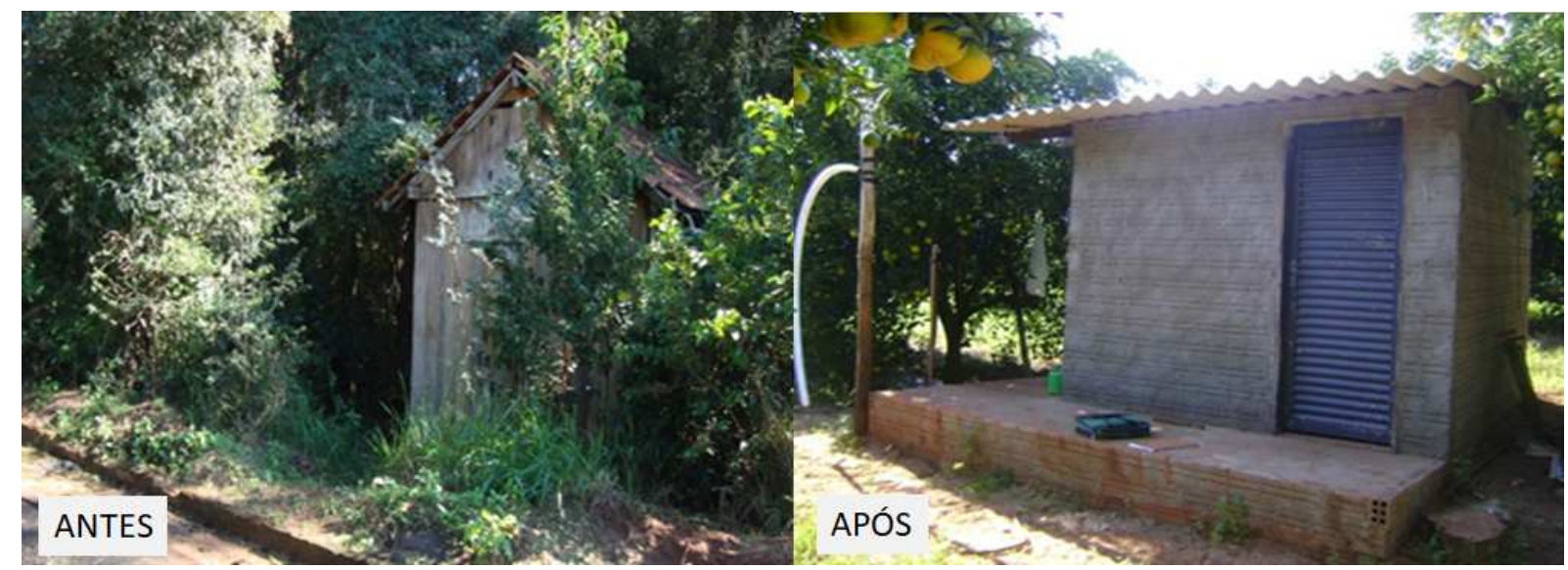

Fonte: Imagem captada durante a pesquisa.

Antes do Fairtrade, os produtores deixavam as embalagens vazias jogadas na propriedade, como se pode ver na Figura 2. Após a certificação, o produtor procurou organizar sua propriedade, construindo ainda um depósito para embalagens vazias (Figura 2), como um dos requisitos para a certificação.

Figura 2 - Depósitos de embalagens vazias antes e após a certificação

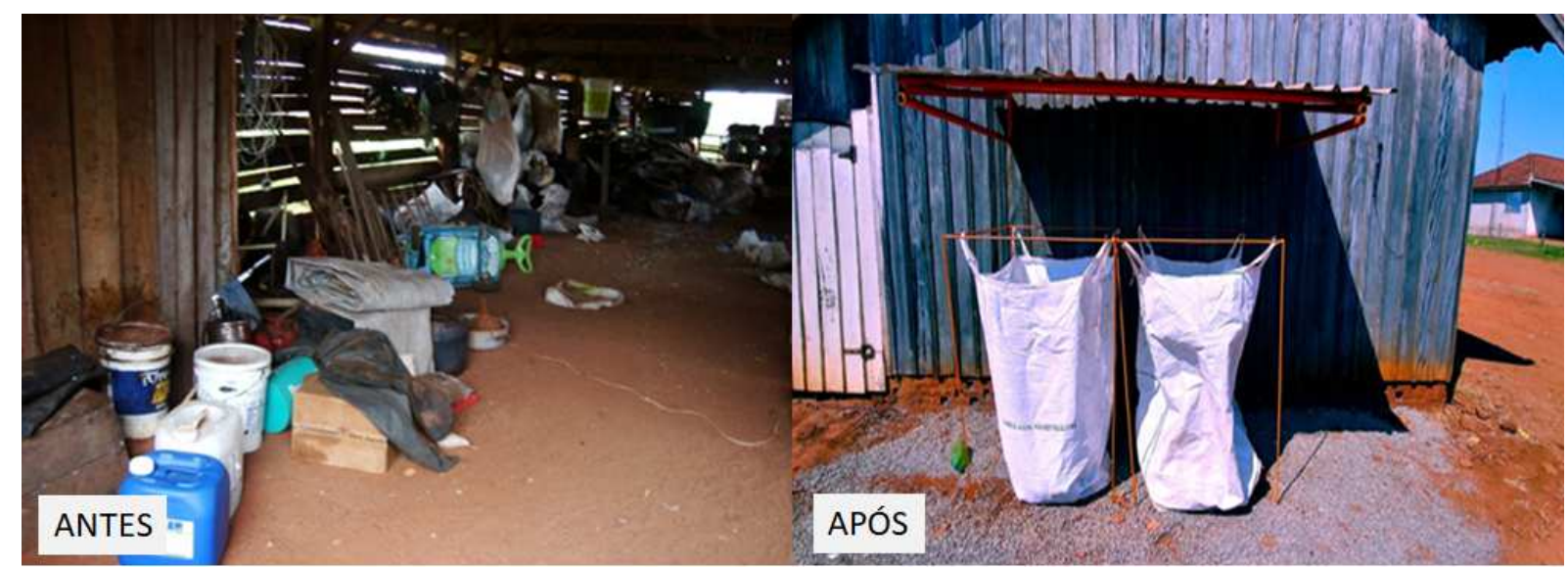

Fonte: Imagem captada durante a pesquisa.

R. gest. sust. ambient., Florianópolis, v. 10, n. 2, p. 25-44, jun. 2021. 
Evidenciou-se com a pesquisa que a inserção dos pequenos produtores no sistema Fairtrade é uma nova forma de competividade que serve como ferramenta de proteção, pois, com a certificação, eles têm a garantia de ingressarem em uma cadeia produtiva em uma posição mais vantajosa devido à comercialização ter foco em um nicho específico de mercado, onde zela-se pelo relacionamento entre produtores, compradores e consumidores, proporcionando, dessa maneira, a valorização do pequeno produtor. De acordo com Sachs (2008, p. 49), "o desafio é transformar pequenos produtores em empresas organizadas de pequenas escala, capazes de competir no mercado capitalista", o que a partir do conceito de comércio justo pautado em práticas sustentáveis demonstrou-se viável tanto socialmente, ambientalmente quanto financeira, ou seja, ambos os desenvolvimento podem ocorrer de forma equilibrada.

\section{CONSIDERAÇÕES FINAIS}

Com este estudo, procurou-se identificar os ganhos percebidos pelos pequenos produtores rurais a partir do conceito de comércio justo e adoção de práticas sustentáveis. Identificou-se que a certificação Fairtrade é uma alternativa para que os pequenos produtos rurais, quando organizados, consigam estar inseridos na cadeia de produção da qual fazem parte, desde o plantio da laranja até a sua comercialização, conseguindo vender seu produto por um preço justo.

Identificou-se que, juntamente com a certificação, vieram novas responsabilidades, tanto para a cooperativa quanto para o produtor, em três áreas principais: econômica, ambiental e social. Essas responsabilidades, quando cumpridas, dão ao produtor mais sustentabilidade em todo o seu negócio. Por meio de uma certificação sustentável, os resultados percebidos foram melhor qualidade de vida para as famílias envolvidas com a produção certificada e sustento com qualidade, vindo da propriedade.

Observou-se ainda que os produtores entrevistados enfrentaram dificuldades devido à baixa escolarização; por outro lado, a cooperativa, visando mitigar esse ponto, ofereceu suporte técnico para auxiliar no cumprimento dos critérios exigidos pela certificação Fairtrade. Na comercialização do produto, no caso a laranja, a cooperativa efetua a negociação com os compradores e realiza o pagamento aos produtores, cabendo a eles cumprir os critérios e entregar a laranja na cooperativa. A

R. gest. sust. ambient., Florianópolis, v. 10, n. 2, p. 25-44, jun. 2021. 
certificadora tem um olhar sobre toda a cadeia produtiva, auditando-a regularmente para garantir ao cliente final que a cooperativa e os produtores estão realmente em conformidade com os critérios estabelecidos.

Com a certificação, identificaram-se ganhos no cuidado com o meio ambiente, com a produção sendo realizada de forma ecologicamente correta; com os direitos dos trabalhadores, sejam eles produtores, sejam colhedores; cuidados com a saúde do homem do campo; e ainda a cultura de produtos mais saudáveis.

No decorrer desta pesquisa pode-se observar que os produtores destacaram os ganhos econômicos, porém evidenciaram-se ganhos ambientais e econômicos, que podem ter sido minimizados pelos entrevistados em decorrência da baixa escolaridade dos mesmos.

Dentre as limitações da pesquisa, destaca-se as entrevistas com os trabalhadores em decorrência do período em que se deram as entrevistas, pois maio é um mês de entressafra da laranja, sendo o início da safra em julho e o fim em janeiro. Neste período tais profissionais estão trabalhando com outras culturas, que não possuem certificação FairTrade. Ainda que tenha-se pesquisado uma população pequena, este estudo deu início a um possível trabalho futuro, que poderá ser aprofundado na demonstração dos ganhos obtididos a partir de práticas sustentáveis.

Destaca-se que a certificação Fairtrade foca seus esforços em apoiar organizações de pequenos produtores para melhorar suas condições de vida e obter ganhos futuros. Em alinhamento com os Objetivos de Desenvolvimento Sustentável, a certificação Fairtrade tem como propósito combater a pobreza e empoderar os produtores de países em desenvolvimento. Possui ainda uma relação com o ODS 2 "Acabar com a fome, alcançar a segurança alimentar e melhoria da nutrição e promover a agricultura sustentável" (BRASIL, 2016, p. 1) e também com o ODS 3 "Assegurar uma vida saudável e promover o bem-estar para todos, em todas as idades" (BRASIL, 2016, p. 1), com as reduções de agroquímicos e os cuidados com o meio ambiente, além do cuidado com o pequeno produtor em suas perspectivas econômica e social, impactando no ODS 8 - "Promover o crescimento econômico sustentado, inclusivo e sustentável, emprego pleno e produtivo e trabalho decente para todos" (BRASIL, 2016, p. 1). O produtor trabalha pensando não somente no hoje, mas no futuro, e reconhece que as dimensões social e ambiental são fundamentais

R. gest. sust. ambient., Florianópolis, v. 10, n. 2, p. 25-44, jun. 2021. 
para a sustentabilidade da certificação e que trazem uma recompensa financeira para o produtor.

\section{REFERÊNCIAS}

ARAÚJO, G. F. Estratégias de sustentabilidade: aspectos científicos, sociais e legais contexto global visão comparativa. São Paulo: Letras Jurídicas, 2008.

ARTESOL. Atuação da Artesol no Comércio Justo. Disponível em: <http://artesol.org.br/comercio-justo/>. Acesso em: 23 dez. 2017.

BARBIERI, Rosa Lía et al. Agricultural biodiversity in Southern Brazil: Integrating efforts for conservation and use of neglected and underutilized species. Sustainability, v. 6, n. 2, p. 741-757, 2014.

BEGNINI, Sergio et al. Capitalismo consciente: uma análise netnográfica em grupos da rede social LinkedIn. Cadernos EBAPE. BR, v. 17, n. 2, p. 277-293, 2019.

BOFF, L. Sustentabilidade: o que é - o que não é. 4. ed. Petrópolis: Vozes, 2015.

BRASIL. Ministério das Relações Exteriores. Objetivos de desenvolvimento sustentável. fev. 2016b. Disponível em: <http://www.itamaraty.gov.br/images/ed_desenvsust/ODSportugues12fev2016.pdf>. Acesso em: 8 set. 2018.

ELKINGTON, J. Sustentabilidade: canibais com garfo e faca. São Paulo: M. Books, 2020.

FAIRTRADE. Fairtrade. Disponível em: <https://www.fairtrade.org.uk/>. Acesso em: 7 set. 2018.

- Guia para certificação Fairtrade de organizações de pequenos produtores: coordenadora latino-americana e do Caribe de pequenos produtores do comércio justo. El Salvador: Faitrade Internacional, 2016.

FRÉMEAUX, Sandrine; MICHELSON, Grant. The common good of the firm and humanistic management: Conscious capitalism and economy of communion. Journal of Business Ethics, v. 145, n. 4, p. 701-709, 2017.

R. gest. sust. ambient., Florianópolis, v. 10, n. 2, p. 25-44, jun. 2021. 
GALINDO, Fabio Lara; WEISS, Marcos Cesar. Deserto Verde ou Inovação para o Desenvolvimento Sustentável: Estudo de Caso de uma Indústria de Celulose no Brasil. FACEF Pesquisa, v. 21, n. 2, 2018.

MACÊDO, I. I. et al. Ética e sustentabilidade. Rio de Janeiro: FGV, 2015. (Série Gestão de Pessoas).

MACKEY. J.; SISODIA, R. Capitalismo consciente: como liberar o espírito heroico dos negócios. São Paulo: HSM, 2013.

MUNCK, L. Gestão da sustentabilidade nas organizações: um novo agir a frente à lógica das competências. São Paulo: Cengage Learning, 2013.

PATRÍCIO, Patrícia Cartes; GOMES, João Carlos Costa. Desenvolvimento Rural Sustentável, Planejamento e Participação. Revista NERA, n. 21, p. 100-113, 2013.

PENÃFIEL, A.; RADOMSKY, G. Desenvolvimento e sustentabilidade. Curitiba: Intersaberes, 2013.

SACHS, I. Desenvolvimento: includente, sustentável, sustentado. Rio de Janeiro: Garamond, 2008.

SANTOS, Laís Silveira; SERAFIM, Mauricio C.; PINHEIRO, Daniel Moraes. Desafios à Compreensão do Comércio Justo como Modelo Econômico Viável: Um Olhar a partir da Sociologia Econômica para os Estudos Organizacionais. Revista Reuna, v. 25, n. 1, p. 73-89, 2020.

SEBRAE. O que é fair trade (comércio justo) jan. 2016. Disponível em: <http://www.sebrae.com.br/sites/PortalSebrae/artigos/o-que-e-fair-trade-comerciojusto,82d8d1eb00ad2410VgnVCM100000b272010aRCRD>. Acesso em: 8 set. 2018. STELZER, Joana; GRANEMANN, Gustavo Kobus. Análise dos Procedimentos de Comércio Justo para Candidatura à Certificação Fairtrade (FLOCERT). Revista Uniabeu, v. 12, n. 31, 2019.

TAMBELINI, F. Justiça seja feita: o movimento batizado de Comércio Justo cresce $37 \%$ ao ano e ajuda pequenos empresários a conquistar o mercado externo. Disponível em: <http://revistapegn.globo.com/Empresasenegocios/0,19125,ERA1674302-29911,00.html>. Acesso em: 7 set. 2018.

R. gest. sust. ambient., Florianópolis, v. 10, n. 2, p. 25-44, jun. 2021. 
WANG, Edward Shih-Tse; CHEN, Yu-Chen. Effects of perceived justice of fair trade organizations on consumers' purchase intention toward fair trade products. Journal of Retailing and Consumer Services, v. 50, p. 66-72, 2019.

WFTO (World Fair Trade Organization) Home of Fair Trade Enterprises. Disponível em: <https://wfto.com/who-we-are\#10-principles-of-fair-trade> Acesso em 14 mar 2021.

R. gest. sust. ambient., Florianópolis, v. 10, n. 2, p. 25-44, jun. 2021. 